Check for updates

Cite this: RSC Adv., 2017, 7, 35012

Received 27th March 2017

Accepted 5th July 2017

DOI: $10.1039 / \mathrm{c} 7 \mathrm{ra03535g}$

rsc.li/rsc-advances

\section{Facile synthesis of uniform magnetic graphitic carbon for an efficient adsorption of pentachlorophenol $\uparrow$}

\author{
Pengpeng Qiu, ${ }^{a}$ Dingyun Cui ${ }^{\mathrm{b}}$ and Jeehyeong Khim (D) *a
}

Uniform core-shell structured magnetic graphitic carbon $\left(\mathrm{Fe}_{3} \mathrm{O}_{4}\left(\mathrm{aSiO}_{2} \mathrm{ag}-\mathrm{C}\right)\right.$ nanospheres were fabricated via a two-step Stöber coating strategy, followed by a carbonization process in $\mathrm{N}_{2}$ atmosphere. The resultant composites possess a large magnetic susceptibility $\left(25 \mathrm{emu} \mathrm{g}^{-1}\right)$ and a high graphitization degree, making it an excellent magnetically separable adsorbent for the removal of pentachlorophenol.
Pentachlorophenol (PCP) is an important chlorinated aromatic organic compound that is widely used as a pesticide, a disinfectant, and a wood preservative. As a result, the concentration of PCP in the aquatic system is continuously increasing year by year. In addition, long-term exposure to PCP, even at very low level concentrations, can cause severe harmful effects on the liver, kidneys, lungs and nervous system of human beings. ${ }^{1}$ Therefore, the development of an efficient technology to treat PCP is necessary. Till now, commonly used strategies include biological degradation, membrane filtration, adsorption, and advanced oxidation technology. ${ }^{2}$ Among them, adsorption has been considered as one of the most practical and reliable technologies because of several advantages such as low cost, high efficiency, and simplicity in operation. ${ }^{3}$ Recently, graphitic carbon ( $\mathrm{g}-\mathrm{C})$ - based materials are of vital importance in this field for their special structure, high rigidity and good chemical stability. ${ }^{4}$ However, they are very difficult to separate and regenerate during application, especially in a slurry operating system. To address this issue, magnetic separation provides a very convenient approach for removing and recycling magnetic particles such as magnetite, ferrite, and barium ferrite by applying external magnetic fields. It has been demonstrated that the incorporation of magnetic components into the adsorbent can greatly enhance the separation and recovery. ${ }^{5}$ To date, several methods (laser assisted irradiation, ${ }^{6}$ thermal plasma, ${ }^{7}$ microwave heating, ${ }^{8}$ chemical vapor condensation, ${ }^{9}$ and hydrothermal ${ }^{10}$ ) have been used for the synthesis of this type of material. However, most of these methods are associated with some disadvantages such as involving relatively harsh reaction conditions, requiring high energy cost, producing

${ }^{a}$ Department of Civil, Environmental and Architectural Engineering, Korea University, Seoul 136-701, Republic of Korea. E-mail: hyeong@korea.ac.kr

${ }^{b}$ Yeongdeok High School, 334 Meyong-ro, Yeongtong-gu, Suwon-si, Gyeonggi-do, Republic of Korea

$\dagger$ Electronic supplementary information (ESI) available. See DOI: $10.1039 / \mathrm{c} 7 \mathrm{ra} 03535 \mathrm{~g}$ materials with aggregated structures, etc. Therefore, to develop a facile method to synthesize uniform magnetic g-C with a high adsorption performance for PCP is very much desired.

Herein, uniform core-shell structured magnetic g-C nanospheres $\left(\mathrm{Fe}_{3} \mathrm{O}_{4} @ \mathrm{SiO}_{2} @ g\right.$-C) have been fabricated via a two-step Stöber coating method, followed by a carbonization process. The introduction of a rigid silica layer between $\mathrm{Fe}_{3} \mathrm{O}_{4}$ core and graphitic carbon shell is to help prevent leaching of $\mathrm{Fe}_{3} \mathrm{O}_{4}$, as well as increase the thermal stability of the resultant core-shell material during the carbonization process. After treated at $850{ }^{\circ} \mathrm{C}$ in $\mathrm{N}_{2}$ gas, the magnetic g-C possesses a well-defined core-shell structure with a large magnetic susceptibility (25 emu $\mathrm{g}^{-1}$ ) and a high graphitization degree. Finally, the magnetic g-C is used as an adsorbent, showing an excellent adsorption capacity for PCP. Moreover, the adsorbent can be easily recycled within $30 \mathrm{~s}$ by using an external magnetic field and the constant adsorption ability is retained even after 5 cycles.

The synthesis strategy for the core-shell structured magnetic $\mathrm{g}$-C nanospheres is depicted in Fig. 1. First, the uniform magnetite particles were coated with a nonporous silica layer through a general Stöber coating approach in the presence of tetraethyl orthosilicate (TEOS) (denoted as $\mathrm{Fe}_{3} \mathrm{O}_{4} @ \mathrm{SiO}_{2}$ ). Then, a layer of resorcinol-formaldehyde (RF) resin was deposited onto the silica layer through interface polymerization of resorcinol and formaldehyde catalyzed by ammonium hydroxide due to the strong electrostatic attraction between resorcinol derivatives and $\mathrm{NH}_{4}^{+}$absorbed on $\mathrm{Fe}_{3} \mathrm{O}_{4} @ \mathrm{SiO}_{2}$ (defined as

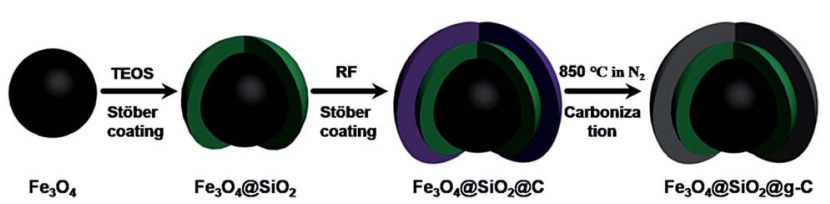

Fig. 1 Schematic illustration for the synthesis of uniform core-shell structured magnetic $\mathrm{g}-\mathrm{C}$. 
$\left.\mathrm{Fe}_{3} \mathrm{O}_{4} @ \mathrm{SiO}_{2} @ \mathrm{RF}\right) .{ }^{11}$ Finally, the resultant composites were carbonized in $\mathrm{N}_{2}$ at $850{ }^{\circ} \mathrm{C}$ (designated as $\mathrm{Fe}_{3} \mathrm{O}_{4} @ \mathrm{SiO}_{2} @ g-\mathrm{C}$ ).

The obtained $\mathrm{Fe}_{3} \mathrm{O}_{4}$ particles possess a uniform spherical shape with an average diameter of $\sim 130 \mathrm{~nm}$ (Fig. 2A). The particles exhibit excellent dispersibility in polar solvents such as water and ethanol because of numerous citrate groups anchored on the surface, facilitating the subsequent coating. The $\mathrm{Fe}_{3} \mathrm{O}_{4} @ \mathrm{SiO}_{2}$ nanospheres after the first Stöber coating process shows a relatively smooth surface with a diameter of $\sim 190 \mathrm{~nm}$ (Fig. 2B). TEM images reveal that a silica layer with a thickness of $\sim 30 \mathrm{~nm}$ is uniformly coated onto the magnetic core, resulting in a well-defined core-shell structure. The further Stöber coating leads to the formation of sandwich-like $\mathrm{Fe}_{3} \mathrm{O}_{4} @ \mathrm{SiO}_{2} @ \mathrm{RF}$ nanospheres with an average diameter of $250 \mathrm{~nm}$, indicating the presence of $\sim 30 \mathrm{~nm}$ thick carbon layer (Fig. 2C). Notably, when the core-shell $\mathrm{Fe}_{3} \mathrm{O}_{4} @ \mathrm{SiO}_{2} @ \mathrm{RF}$ samples after being carbonized at $850{ }^{\circ} \mathrm{C}$ in nitrogen, discrete and uniform nanospheres are well retained (Fig. 2D). However, the delocalization of $\mathrm{Fe}_{3} \mathrm{O}_{4}$ cores was observed, which is possibly resulted from the recrystallization of $\mathrm{Fe}_{3} \mathrm{O}_{4}$ but inhibited by the outer silica shell. The energy-dispersive X-ray (EDX) of the magnetic g-C (Fig. S1†) clearly showed the characteristic peaks of titanium, carbon, silica and oxygen, suggesting the possible coexistence of $\mathrm{Fe}_{3} \mathrm{O}_{4}, \mathrm{SiO}_{2}$, and carbon. In

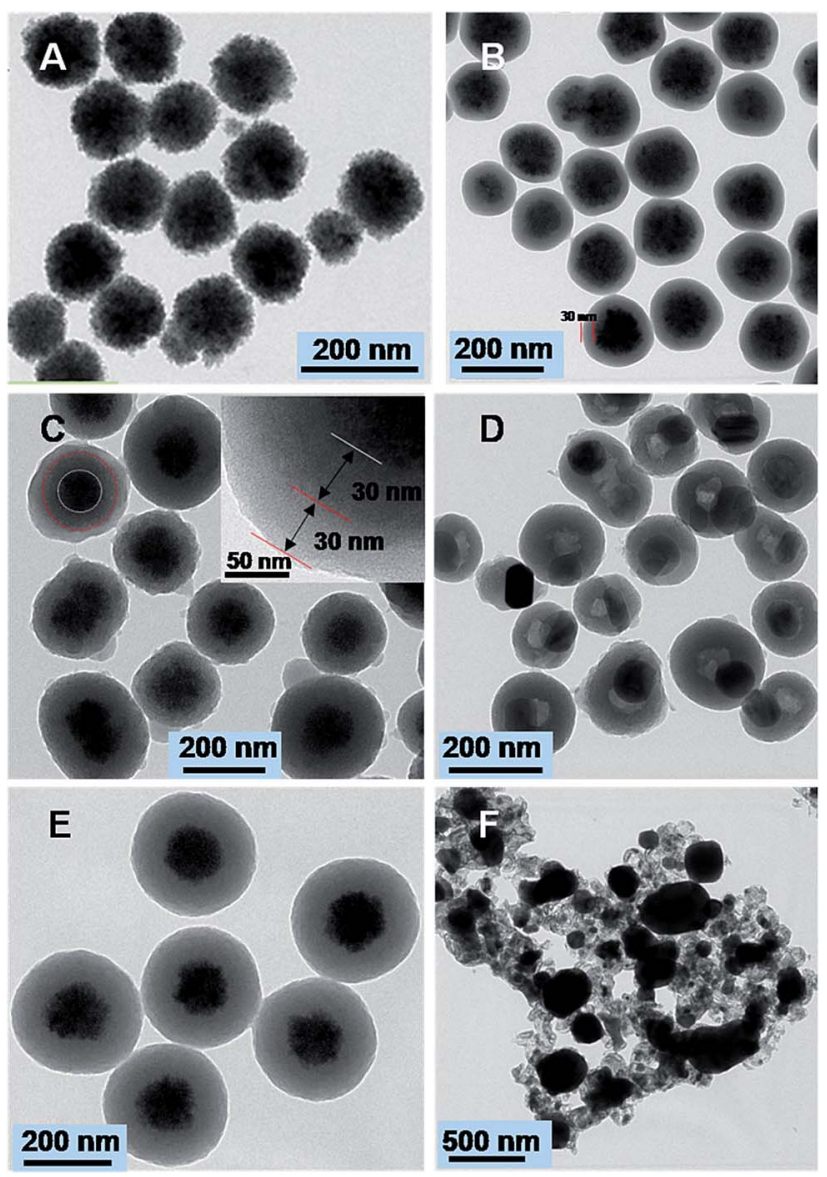

Fig. 2 TEM images of the $\mathrm{Fe}_{3} \mathrm{O}_{4}$ nanoparticles (A), $\mathrm{Fe}_{3} \mathrm{O}_{4} \mathrm{QSiO}_{2}$ coreshell nanostructures (B), $\mathrm{Fe}_{3} \mathrm{O}_{4} \mathrm{aSiO}_{2} \mathrm{aRF}(\mathrm{C}), \mathrm{Fe}_{3} \mathrm{O}_{4}\left(\mathrm{aSiO}_{2} \mathrm{ag}-\mathrm{C}(\mathrm{D})\right.$, $\mathrm{Fe}_{3} \mathrm{O}_{4} \mathrm{QRF}(\mathrm{E})$, and $\mathrm{Fe}_{3} \mathrm{O}_{4} \mathrm{ag}-\mathrm{C}(\mathrm{F})$ nanospheres. contrast, when carbonizing $\mathrm{Fe}_{3} \mathrm{O}_{4} @ \mathrm{RF}$ sample at the same temperature without the silica layer coating (Fig. 2E), the welldefined core-shell structures were completely collapsed and the magnetite cores were gathered into a larger particle (Fig. 2F), indicating the importance of silica interlayer towards increasing the thermal stability of the resultant composites.

The XRD patterns (Fig. 3A) of the $\mathrm{Fe}_{3} \mathrm{O}_{4} @ \mathrm{RF}$ and $\mathrm{Fe}_{3} \mathrm{O}_{4} @ \mathrm{C}$ $450\left(\mathrm{Fe}_{3} \mathrm{O}_{4} @ \mathrm{RF}\right.$ sample carbonized at $\left.450{ }^{\circ} \mathrm{C}\right)$ core-shell nanospheres display several broad characteristic diffraction peaks at $2 \theta=30.1,35.4,43.1,56.9$, and $62.5^{\circ}$, which are typical for $\mathrm{Fe}_{3} \mathrm{O}_{4}$ crystalline phase (can be indexed as 220, 311, 400, 511, and 440, respectively). Compared with the pristine sample, diffraction peak attributed to the graphite (002) was also found in the XRD pattern of the $\mathrm{Fe}_{3} \mathrm{O}_{4} @ \mathrm{SiO}_{2} @ g$-C composites, suggesting that the $\mathrm{RF}$ was well carbonized into g-C. ${ }^{12}$ In addition, the iron peaks at $2 \theta=44.6$ and $49.4^{\circ}$ were detected, which is possibly due to the inhibition effect of silica towards the crystallization of $\mathrm{Fe}_{3} \mathrm{O}_{4}$. The formation of iron in the composites could be attributed to the reducibility of carbon. Notably, this is good for the formation of magnetic $\mathrm{g}$-C with a large magnetic property because iron (200 emu $\mathrm{g}^{-1}$ ) typically exhibits a larger magnetization than the magnetite $\left(50-80\right.$ emu $\left.\mathrm{g}^{-1}\right) .{ }^{13}$ Unlike the $\mathrm{Fe}_{3^{-}}$ $\mathrm{O}_{4} @ \mathrm{SiO}_{2} @ g-\mathrm{C}$ sample, the XRD pattern of the core-shell $\mathrm{Fe}_{3} \mathrm{O}_{4} @ g$-C sample shows intense crystalline diffraction peaks at $2 \theta=33.7$ and $42.6^{\circ}$, in accordance with $\mathrm{FeO}$ crystals (diamagnetic), which gives a bad effect on the magnetic property of the resultant composites, further revealing the priority of coating a silica interlayer. To check the graphitic character of the resultant composites, the Raman spectra was recorded in the range of $500-2500 \mathrm{~cm}^{-1}$ (Fig. 3B). In the Raman spectra of the resultant composites, the appearance of two prominent peaks $D\left(1368 \mathrm{~cm}^{-1}\right)$ and $\mathrm{G}\left(1590 \mathrm{~cm}^{-1}\right)$ are assigned to the disordered hybridized carbon atoms $\left(\mathrm{A}_{1 \mathrm{~g}}\right)$ and the stretching vibrations of $\mathrm{sp}^{2}$ bonds of perfect graphite crystals $\left(\mathrm{E}_{2 \mathrm{~g}}\right.$ mode), respectively. It is widely believed that the intensity ratio of the $\mathrm{D}$ and $\mathrm{G}$ bands, $I_{\mathrm{D}} / I_{\mathrm{G}}$, is a measure of the crystallinity of carbon. ${ }^{\mathbf{1 4}}$ The relatively small $I_{\mathrm{D}} / I_{\mathrm{G}}$ ratio of magnetic $\mathrm{g}$-C over other samples indicates the low density of the disordered $\mathrm{sp}^{2}-$ hybridized carbon atoms, suggesting a high graphitization degree of the magnetic $\mathrm{g}$-C.

The performance of the resultant magnetic g-C composites for the adsorptive removal of PCP was evaluated at $\mathrm{pH} 6.8$ (Fig. 4A). As a control, the adsorption performances of PCP in the presence of pristine $\mathrm{Fe}_{3} \mathrm{O}_{4} @ \mathrm{RF}$ and $\mathrm{Fe}_{3} \mathrm{O}_{4} @ \mathrm{C}-450$ were also tested, exhibiting the adsorption capacity of 3.0 and $4.8 \mathrm{mg} \mathrm{g}^{-1}$,

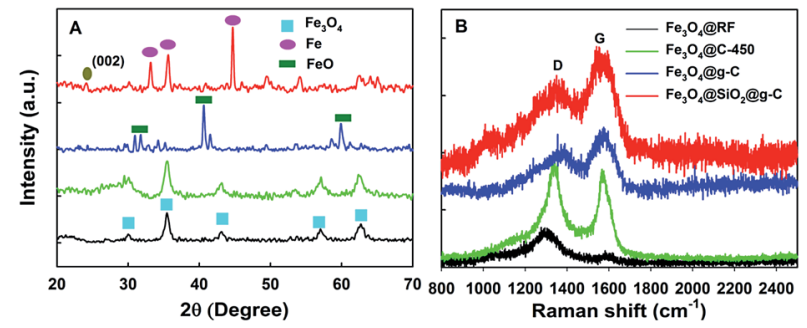

Fig. 3 (A) The XRD patterns and (B) Raman spectra of various adsorbents. 

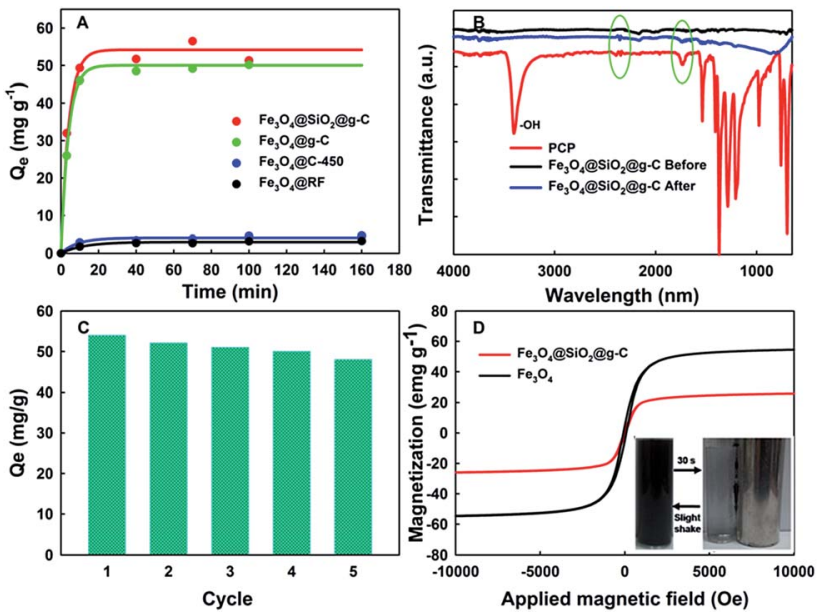

Fig. 4 (A) Adsorption performance of PCP in the present of various adsorbents, (B) the FTIR spectra of magnetic g-C before and after PCP adsorption, (C) the magnetic hysteresis loops at $300 \mathrm{~K}$ (insert shows the magnetic separation via a hand-held magnet), and (D) the recycle test of the magnetic $\mathrm{g}-\mathrm{C}$.

respectively. The comparable adsorption performance of these two materials was possibly attributed to the similar BET surface areas (Fig. S2†). Interestingly, when the magnetic g-C was used as an adsorbent, the adsorption capacity was sharply increased. It has been found that the absorption capacity of the magnetic $\mathrm{g}$-C with silica coating is $55 \mathrm{mg} \mathrm{g}^{-1}$, which is larger than that of the magnetic $\mathrm{g}-\mathrm{C}$ without silica coating $\left(50 \mathrm{mg} \mathrm{g}^{-1}\right.$ ), further revealing the importance of coating a silica interlayer. More importantly, this value is much higher than that of previous magnetic adsorbent developed for the removal of PCP (35$50 \mathrm{mg} \mathrm{g}{ }^{-1}$, Table $\left.\mathrm{S} 1 \dagger\right) .{ }^{15}$ The BET surface area normalized adsorption capacity $\left(2.30 \mathrm{mg} \mathrm{m}^{-2}\right)$ is $3-5$ times larger than that of magnetic biochar based adsorbent, indicating the magnetic $\mathrm{g}$-C possesses more effective surface area. The excellent adsorption performance of magnetic $\mathrm{g}-\mathrm{C}$ can be attributed to not only the relative large BET surface area (Fig. S1 $\dagger$ ) but also the $\pi-\pi$ interaction between the PCP molecules and $\mathrm{g}-\mathrm{C}$, which was demonstrated by FTIR spectra (Fig. 4B). In the FTIR spectra, the peak at $3425 \mathrm{~cm}^{-1}$ is related to the hydroxyl group. However, in the spectra of $\mathrm{Fe}_{3} \mathrm{O}_{4} @ \mathrm{SiO}_{2} @ g-\mathrm{C}$, this peak was not observed, indicating the surface of the magnetic $\mathrm{g}$ - $\mathrm{C}$ is full of $\mathrm{C}=\mathrm{C}$ or $\mathrm{C}=\mathrm{O}$ bond. The many characteristic peaks of PCP (e.g. 2300-2400 and 1700-1800 $\mathrm{cm}^{-1}$ ) were also detected on magnetic g-C after adsorption, indicating that PCP is adsorbed on the magnetic g-C. In addition, the $\mathrm{C}=\mathrm{C}$ peak of magnetic g-C after adsorption shifts from $\sim 1524$ to $\sim 1552$ $\mathrm{cm}^{-1}$, which can be attributed to the $\pi-\pi$ interactions between the benzene rings PCP and magnetic g-C. ${ }^{5 c, 16}$ In addition, this adsorbent can also be used to efficiently remove other aromatic emerging organic pollutants (Fig. S3†) such as bisphenol-A (BPA, $25 \mathrm{mg} \mathrm{g}^{-1}$ ) and rhodamine B (RhB, $59 \mathrm{mg}$ $\left.\mathrm{g}^{-1}\right)$. However, the larger adsorption capacity of RhB than BPA could be attributed to that the former one possessed more $\pi-\pi$ interaction forces resulted from the presence of more aromatic rings (Fig. S3B and $\mathrm{C}_{\dagger}^{\dagger}$ ).
The recycle adsorption test of the core-shell structured $\mathrm{Fe}_{3}$ $\mathrm{O}_{4} @ \mathrm{SiO}_{2} @ \mathrm{~g}-\mathrm{C}$ was also examined (Fig. 4C). After five recycles, the adsorption performance of the recovered adsorbent was slightly reduced $(12 \%)$, indicating the good reusability of this material. Notably, no ion ions were detected when leaving the magnetic $\mathrm{g}-\mathrm{C}$ in acidic solution with a $\mathrm{pH}=3$, which is attributed to the protecting effect by the silica interlayer. However, the material cannot be worked in a strong alkaline solution because the silica interlayer could be etched by the alkali, affecting the longevity of the adsorbent. ${ }^{17}$ To investigate the magnetic capacity of the resultant composites, the magnetization (an indicator of the magnetic property) was measured. The magnetization saturation values of pristine $\mathrm{Fe}_{3} \mathrm{O}_{4}$ particles and $\mathrm{Fe}_{3} \mathrm{O}_{4} @ \mathrm{SiO}_{2} @ g$-C are detected to be $\sim 58.4$ and $25.0 \mathrm{emu} \mathrm{g}^{-1}$, respectively (Fig. 4D). As a result of the superparamagnetic property and high magnetization, the core-shell $\mathrm{Fe}_{3} \mathrm{O}_{4}$ @$\mathrm{SiO}_{2} @ \mathrm{~g}-\mathrm{C}$ nanospheres in their homogeneous dispersion show fast motion under the applied magnetic field (become transparent within $30 \mathrm{~s}$ ) and quick dispersibility upon a slight shake when the magnetic field is removed (Fig. 4D insert).

In summary, we report the synthesis of uniform core-shell structured magnetic g-C via a successive Stöber coating strategy, which is facile, mild and effective. The resultant $\mathrm{Fe}_{3} \mathrm{O}_{4}$ @$\mathrm{SiO}_{2}$ @g-C nanospheres possess well-defined core-shell structure with a large magnetic susceptibility $\left(\sim 25.0\right.$ emu $\left.\mathrm{g}^{-1}\right)$, a relatively large BET surface area $\left(25.7 \mathrm{~m}^{2} \mathrm{~g}^{-1}\right)$, and a high graphitization degree. Then, it was demonstrated as an adsorbent for the removal of PCP, showing an excellent adsorption capacity (55 $\mathrm{mg} \mathrm{g}^{-1}$ ), which is much higher than that of the previous magnetic adsorbent (35-50 $\mathrm{mg} \mathrm{g}^{-1}$ ). In addition, it exhibits an excellent reusability (adsorption capacity remaining constant after 5 cycles) and fast magnetic separation capacity (magnetic separation time < $30 \mathrm{~s}$ ). This study paves a great way to synthesize and design a magnetic adsorbent for efficiently removal of PCP.

\section{Acknowledgements}

We thank the Korea Mine Reclamation Corporation (MIRECO, Q1512631) for the financial support.

\section{Notes and references}

1 (a) J. P. DiVincenzo and D. L. Sparks, Environ. Sci. Technol., 1997, 31, 977-983; (b) Research watch: pentachlorophenol exposure, Environ. Sci. Technol., 1998, 32, 511A; (c) K. Kim, P. Qiu, M. Cui and J. Khim, Chem. Eng. J., 2016, 284, 11651173.

2 (a) O. Rubilar, G. Feijoo, C. Diez, T. A. Lu-Chau, M. T. Moreira and J. M. Lema, Ind. Eng. Chem. Res., 2007, 46, 6744-6751; (b) J. Lin, Y. He, J. Xu, Z. Chen and P. C. Brookes, J. Agric. Food Chem., 2014, 62, 9974-9981; (c) C. Visvanathan, L. N. Thu, V. Jegatheesan and J. Anotai, Desalination, 2005, 183, 455464; (d) F. J. Benítez, J. L. Acero, A. I. Leal and F. J. Real, J. Hazard. Mater., 2008, 152, 373-380; (e) I. Oller, S. Malato and J. A. Sánchez-Pérez, Sci. Total Environ., 2011, 409, 4141-4166. 
3 (a) A. J. Slaney and R. Bhamidimarri, Water Sci. Technol., 1998, 38, 227-235; (b) X. Xue, K. Hanna, M. Abdelmoula and N. Deng, Appl. Catal., B, 2009, 89, 432-440.

4 (a) J. Liu, T. Zhang, Z. Wang, G. Dawson and W. Chen, J. Mater. Chem., 2011, 21, 14398-14401; (b) K. Yang and B. Xing, Chem. Rev., 2010, 110, 5989-6008.

5 (a) L. Sun, C. Tian, L. Wang, J. Zou, G. Mu and H. Fu, J. Mater. Chem., 2011, 21, 7232-7239; (b) H. Niu, Y. Wang, X. Zhang, Z. Meng and Y. Cai, ACS Appl. Mater. Interfaces, 2012, 4, 286-295; (c) Z. Jin, X. Wang, Y. Sun, Y. Ai and X. Wang, Environ. Sci. Technol., 2015, 49, 9168-9175; (d) P. Qiu, W. Li, B. Thokchom, B. Park, M. Cui, D. Zhao and J. Khim, J. Mater. Chem. A, 2015, 3, 6492-6500.

6 J. B. Park, S. H. Jeong, M. S. Jeong, J. Y. Kim and B. K. Cho, Carbon, 2008, 46, 1369-1377.

7 J. H. Byeon and J.-W. Kim, ACS Appl. Mater. Interfaces, 2010, 2, 947-951.

8 M. Bystrzejewski, Z. Karoly, J. Szepvolgyi, W. Kaszuwara, A. Huczko and H. Lange, Carbon, 2009, 47, 2040-2048.

9 D. S. Jacob, I. Genish, L. Klein and A. Gedanken, J. Phys. Chem. B, 2006, 110, 17711-17714.

10 (a) S. H. Yu, X. J. Cui, L. L. Li, K. Li, B. Yu, M. Antonietti and H. Cölfen, Adv. Mater., 2004, 16, 1636-1640; (b) X. Sun and Y. Li, Angew. Chem., Int. Ed., 2004, 43, 597-601.
11 Q. Yue, J. Li, W. Luo, Y. Zhang, A. A. Elzatahry, X. Wang, C. Wang, W. Li, X. Cheng, A. Alghamdi, A. M. Abdullah, Y. Deng and D. Zhao, J. Am. Chem. Soc., 2015, 137, 1328213289.

12 G. Sun, X. Li, Y. Qu, X. Wang, H. Yan and Y. Zhang, Mater. Lett., 2008, 62, 703-706.

13 (a) J. Crangle and G. M. Goodman, Math. Phys. Sci., 1971, 321, 477-491; (b) Y. Liu, Y. Wang, S. Zhou, S. Lou, L. Yuan, T. Gao, X. Wu, X. Shi and K. Wang, ACS Appl. Mater. Interfaces, 2012, 4, 4913-4920.

14 (a) P. Qiu, B. Park, J. Choi, M. Cui, J. Kim and J. Khim, J. Alloys Compd., 2017, 70, 67-15; (b) A. C. Ferrari, Solid State Commun., 2007, 14, 47-57.

15 (a) P. Devi and A. K. Saroha, Bioresour. Technol., 2014, 169, 525-531; (b) L. Zhou, S. Pan, X. Chen, Y. Zhao, B. Zou and M. Jin, Chem. Eng. J., 2014, 257, 10-19; (c) P. Devi and A. K. Saroha, Chem. Eng. J., 2015, 271, 195-203; (d) J. Yang, J.-Y. Li, J.-Q. Qiao, S.-H. Cui, H.-Z. Lian and H.-U. Chen, Appl. Surf. Sci., 2014, 32, 1126-1135.

16 L. Wang, C. Tian, G. Mu, L. Sun, H. Zhang and H. Fu, Mater. Res. Bull., 2012, 47, 646-654.

17 P. Qiu, K. Kang, K. Kim, W. Li, M. Cui and J. Khim, RSC Adv., 2015, 5, 96201-96204. 